\title{
Kemoterapi Alan Mide Kanserli Bir Vakanın Roy Adaptasyon Modeli'ne Göre Hemşirelik Bakımı
}

\author{
Nursing Care According to Roy Adaptation Model in A \\ Patient with Chemotherapy Treated Gastric Cancer
}

Handan Eren ${ }^{1}$,

Mahinur Durmuş İskender ${ }^{2}$

${ }^{1}$ Karamanoğlu Mehmetbey Üniversitesi

Sağlık Bilimleri Fakültesi Hemşirelik Esasları $A D$, Karaman, Türkiye

${ }^{2}$ Kastamonu Üniversitesi Taşköprü Meslek

Yüksekokulu Tıbbi Hizmetler ve Teknikler

Bölümü, Kastamonu, Türkiye

Gelis Tarihi/Received: 18 Ocak 2018

Kabul Tarihi/Accepted: 05 Temmuz 2018

Yazışma Adresi: Handan Eren, Karamanoğlu Mehmetbey Üniversitesi Sağlık Bilimleri Fakültesi Hemşirelik Esasları AD, Karaman, Türkiye

e-posta: erennhandan@gmail.com

ORCID

Handan Eren

https://orcid.org/0000-0002-6507-5690

\begin{abstract}
Öz
Mide kanseri sık görülen kanserler arasındadır ve kemoterapi tedavi planı arasında yer almaktadır Birçok sistemi etkileyen bu tedavi yönteminde bireyin ve çevresinin bu sürece uyumu önemlidir. Bu uyumu artırmak amacıyla makalede Roy Adaptasyon Modeli'ne göre ilk kemoterapi kürünü almaya gelen mide kanserli hastaya verilen hemşirelik bakım süreci anlatılmıştır. Hastadan izin alınarak elde edilen veriler doğrultusunda hastaya; fiziksel harekette bozulma, anksiyete, kemoterapi tedavi sürecine yönelik bilgi eksikliği, bireysel baş etmede yetersizlik, aile içi süreçlerde güçlenmeye hazır oluş hemşirelik tanıları konulmuş, uygun hemşirelik girişimleri yapılmıştır. Modelin kemoterapi tedavisi alan hastalarda kullanılabilir olduğu düşünülmüştür.
\end{abstract}

Anahtar Kelimeler: Kemoterapi, roy adaptasyon modeli, hemşirelik bakımı

\section{Abstract}

Gastric cancer is among the common cancers and chemotherapy is among the treatment plan Chemotherapy affects many systems, it is important for the individual and her environment to adapt to this process. In order to improve this adaptation, the nursing care process given to the patient with gastric cancer who was receiving the first chemotherapy treatment according to the Roy Adaptation Model was described. According to the data obtained by the permission of the patient, impaired physical mobility, anxiety, deficient knowledge about chemotherapy treatment process, defensive coping, readiness for enhanced family coping, nursing diagnoses were made and appropriate nursing interventions were applied. The model is thought to be available to patients receiving chemotherapy treatment.

Keywords: Chemotherapy, roy adaptation model, nursing care

\section{GíRiş}

Mide kanseri diğer kanserler arasında görülme sıklığı açısından dördüncü sırada yer almaktadır. Kansere bağlı ölüm sıklığında ise üçüncü sırada gelmektedir (1). Gelişmiş ülkelerde görülme sıklığı azalırken ülkemizde ikinci sırada görülen kanserlerdendir (2). Helicobakter pylori enfeksiyonu, önceden geçirilmiş mide cerrahisi, anemi, gastrit ve genetik faktörler mide kanserinin risk faktörleri arasındadır ve kadınlarda erkeklere oranla daha sık görülmektedir. Erken evrelerde belirti bulgulara çok rastlanmayabilmektedir ancak ilerleyen evrelerde kilo kaybı, kusma, gastrik ağrı ve anoreksiya görülebilmektedir. Tedavide tümörün bulunduğu bölgeye göre cerrahi girişim, kemoterapi, radyoterapi, kemoradyoterapi gibi yöntemler izlenmektedir (3-5). Bu tedavi yöntemlerinden olan kemoterapi uygulamasında tedavinin tümör hücreleri dışında normal hücrelere de etki etmesi sonucu istenmeyen bulgular ortaya çıkabilmektedir. Anemi, trombositopeni, nötropeni, uygulama bölgesine yönelik ekstravazasyon, nörolojik, kardiyolojik, hepatik, pulmoner, gastrointestinal kısaca bütün sistemleri etkileyen semptomlar görülebilmektedir (68). Hastanın yaşam kalitesini önemli ölçüde etkileyen bu semptomların yönetimi hemşireler için önemli bir konudur (9). Birçok sistemi etkileyen kemoterapi tedavisinde de bütüncül hemşirelik bakımı esastır. Profesyonel bir disiplin olan hemşirelikte, bakım uygulamalarının bilimsel bilgi kaynağını kavram ve kuramlar oluşturmaktadırve bu uygulamalar hemşirelik modelleri ile gerçekleştirilmektedir (10). Model kullanımı bakımı sistematize ederek, hemşirelerin tıbbi uygulamalardan çok hemşirelik uygulamalarına odaklanmasını sağlamaktadır $(10,11)$. Hemşirelik modellerinden olan Roy Adaptasyon Modeli (RAM) hemşirelikte yaygın olarak kullanılan ve bireyin adaptif sistemine odaklanan bir modeldir (12). Bireyi ve çevresini etkileyen kanser ve tedavi sürecinde hemşirelik bakımının uygulamasında bu modelin
Atıf yapmak için: Eren H, İskender MD. Kemoterapi Alan Mide Kanserli bir Vakanın Roy Adaptasyon Modeli'ne Göre Hemşirelik Bakımı. Selcuk Med J 2019;35(1): 58-62
Açıklama: Yazarların hiçbiri, bu makalede bahsedilen herhangi bir ürün, aygut veya ilac ile ilgili maddi cıkar ilişkisine sahip değildir Araştırma, herhangi bir dis organizasyon tarafından desteklenmedi Yazarlar calışmanı birincil verilerine tam erişim izni vermek ve derginin talep ettiği takdirde verileri incelemesine izin vermeyi kabul etmektedirler. 
kullanılabileceği düşünülmüştür.

\section{Roy Adaptasyon Modeli (RAM)}

Çocuk hemşiresi olarak görev yapan Callista Roy'un modelin temeli olan düşünceyi oluşturmasında çocukları gözlemlemesi önemli bir etken olmuştur. Klinik deneyimi sırasında çocukların daha hızlı iyileşme gösterdiklerini, değişikliklere daha kolay adapte olduklarını görmüştür. Ayrıca California Üniversitesi'nde görev yaptığı süreçte, kafa travmaları sonrası bilişsel fonksiyonların gelişmesinde hemşirelik modelleri kullanılarak verilen bakımın etkinliği üzerinde çalışmalar yapmıştır. Klinik ve akademik deneyimleri sonucu Roy adaptasyon teorisini formüle etmiştir. Modelde, birey adaptif bir sistem olarak çevre ile etkileşime girerek sürekli uyumu sağlamaya çalışmaktadır $(12,13)$. Hemşire ise bu adaptif sistemlere uyaran sağlayarak adaptasyonu artırmakla sorumludur. Bunun için hemşirelik sürecinde uyaranları bulmalı ve bireyin onlara yönelik olumlu adaptif tepkilerini artıracak girişimlerde bulunmalıdır (12). Roy'a göre insan ile çevre arasında sürekli bir etkileşim bulunmaktadır ve uyaranlar bireyi etkilemektedir. $\mathrm{Bu}$ etki ise bireyin davranışlarına yansımaktadır. Modelde tanımlanan üç çeşit uyaran bulunmaktadır. Bunlar odak uyaran, bağlamsal uyaran ve rezidüel uyaran olarak sıralanmaktadır. Odak uyaranlar bireyi en fazla etkileyen ve dikkatini yönelttiği; bağlamsal uyaranlar, odak uyarana neden olan veya tetikleyen; rezidüel uyaran ise bireyin iç veya dış çevresinde olan fakat diğer uyaranlardan farklı olarak henüz davranışa etkisi belirlenmemiş veya belirsiz olan uyaranlardır (12). Birey bu uyaranlara 4 temel adaptasyon biçiminde uyum sağlamaktadır $(13,14)$. Bunlar;

Fizyolojik adaptasyon biçimi: Çevreden gelen uyarıların fiziksel bir varlık olan birey tarafından yanıtlanma biçimi olarak tanımlanmaktadır. Burada amaç fiziksel bütünlüğün sağlanmasıdır. Oksijenlenme, beslenme, aktivite ve dinlenme, boşaltım, korunmaya yönelik bütün fizyolojik gereksinimler bu biçimde tanımlanmaktadır.

Benlik kavramı adaptasyon biçimi: Fizyolojik adaptasyon biçiminin dışında bireyin kendi hakkındaki duygu, düşünce ve inançlarının bütününü kapsamaktadır. Roy'a göre fiziksel benlik ve kişisel benlik olmak üzere iki temel alandan oluşmaktadır. Fiziksel benlik bireyin kendi bedeni hakkındaki düşüncelerini, kişisel benlik ise bireyin idealleri, ahlaki değerleri ve davranışlarını kapsamaktadır $(13,14)$.

Rol fonksiyon adaptasyon biçimi: Bireyin toplumdaki rolünü yerine getirmesi ve toplum tarafından beklenen birincil, ikincil, üçüncül rollerin gerekenlerini yapmasını içermektedir. Birey sahiplendiği rolden başka bir role geçerken de değişen role ilişkin davranışları göstermelidir $(12,15)$.

Karşılıklı bağlılık adaptasyon biçimi: Bireyin değer verdiği insanlar ve destek sistemleri arasındaki ilişkinin alıcı davranış ve yardımcı davranış biçimleriyle bütünlüğünün sağlanmasını amaçlamaktadır (14).

Bu makalede mide kanseri tanısı alan, cerrahi sonrası intravenöz kemoterapi tedavi sürecine başlayan bir olguda RAM'ne göre bireyin tanılanması, hemşirelik girişimlerin belirlenmesi, uygulanması ve değerlendirilmesi amaçlanmıştır. Bireyden sözel ve yazılı olarak izin alındıktan sonra alınan veriler doğrultusunda hemşirelik bakımı uygulanmıştır.

\section{OLGU}

Olgu 68 yaşında, $155 \mathrm{~cm}$ boyunda, $52 \mathrm{~kg}$ ağırlığındadır. Ev hanımı olan A.Y. 5 çocuk sahibi ve yalnız yaşamaktadır. 2013 yılında hipertansiyon tanısı, bir yıl sonrasında ise demir eksikliği anemisi tanısı alan hasta 1 yı önce bulantı, kusma, iştahsızlık ve kilo kaybı şikâyeti ile dahiliye kliniğine başvurmuştur. Yapılan tetkikler sonucu 2 ay önce mide kanseri tanısı almıştır. Bir hafta öncesinde gastrektomi olan hasta cerrahi sonrası ilk kürünü 18.12.2017 tarihinde almak için bir üniversite hastanesinin ayaktan kemoterapi ünitesine başvurmuştur. 5-Fluorouracil ve Folinik asit alacak olan hastanın kemoterapi tedavisi öncesi laboratuvar (15.12.2017) bulguları Tablo 1'de verilmiştir.

\section{Fizik Muayene}

Genel durumu iyi. Deri turgoru iyi. Kan Basıncı: 110/70 mmHg, nabız: $78 / \mathrm{dk}$, vücut Isısı: $36,1{ }^{\circ} \mathrm{C}$, solunum: 24/dk (Hareketle solunum hızı artmakta), ağrı: 0 (Görsel ağrı skalasına göre). Kifoz mevcut. Operasyona bağlı olarak hastada ağrı olabileceği endişesi ile hareket etmekte güçlük çektiği görülmüştür. İlk kürünü alacağı için endişe duyduğunu belirten hasta bundan sonraki tedavi süreci hakkında bilgisi olmadığı ve sürecin takibini kızları yapacağı için üzgün olduğunu belirtmiştir. Aynı zamanda bu süreçte onların yanında olmasının kendini güvende

Tablo 1. Olgunun kemoterapi tedavisi öncesi laboratuar bulguları

\begin{tabular}{|c|c|c|}
\hline Hemoglobin (HGB) & $11,6 \mathrm{~g} / \mathrm{dL}$ & Nötrofil $57,9 \%$ \\
\hline Hematokrit (Hct) & $32,7 \%$ & Eozinofil 0,7 \% \\
\hline Eritrosit & $4,09 \mathrm{~mm} 3$ & $23 \mathrm{UL}$ \\
\hline Lökosit & 7,55 bin & $12 U L$ \\
\hline
\end{tabular}



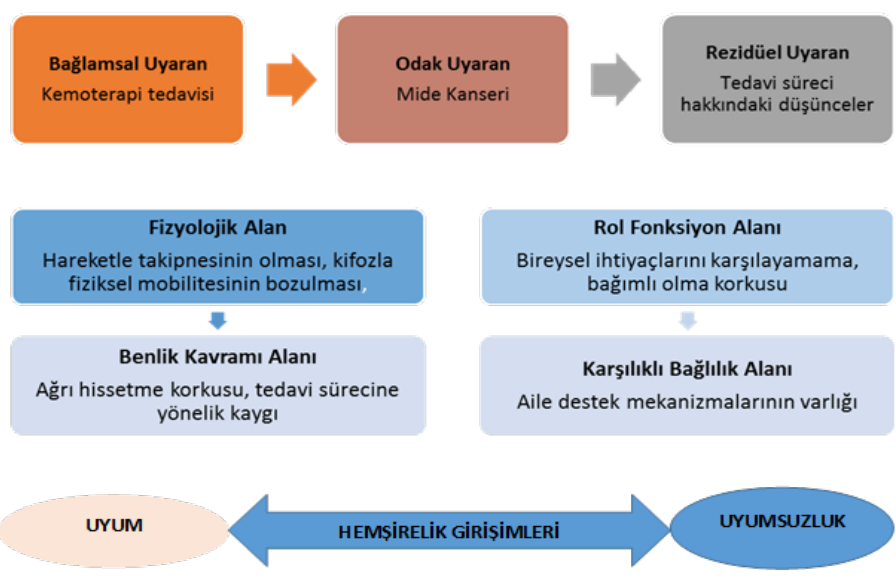

Şekil 1. Mide Kanserli Hastanın Hemşirelik Bakımında Roy Adaptasyon Modeli

hissetmesine neden olduğunu iletmiştir. AY'nin bakımında RAM modeline göre öncelikle bireyin mide kanseri tanısını aldıktan sonraki gerçekleştirilen cerrahi girişim ve kemoterapi tedavisi hakkında bilgi eksikliğinin giderilmesi, tedavide yer alan ilaçların etkilerine ve tedavi kürüne kendinin ve yakınlarının uyumunu sağlamak için gerekli uygulamaların planlanıp, uygulanması ve değerlendirilmesi gerekmektedir (Şekil 1).

\section{Fizyolojik Alan}

Odak uyaran: Cerrahi operasyon

Bağlamsal uyaran: Yaşa bağlı olarak hareketlerin kısıtlanması, kifoz

Rezidüel uyaran: Ağrı hissedeceği hakkında endişe duyması

\section{Hemşirelik Tanısı: Fiziksel Harekette Bozulma} Hemşirelik Girişimleri

- Range of Motion (ROM) egzersizleri gösterilir.

- Egzersiz öncesi ve sonrası yaşamsal bulgular takip edilir.

- Aynı pozisyonda uzun süre durmaması gerektiği söylenir.

- Ağrıya neden olabilecek hareketler konusunda konuşulur.

- Cerrahi bölgenin korunması hakkında eğitim verilir.

- Günlük aktivitelerinde daha yavaş ve kısa süreli, dinlenme periyotları oluşturması hakkında bilgi verilir.

- Güvenli ayakkabı kullanımı ve çevresel engellerin tanınması hakkında eğitim verilir.

- Gerekirse yardımcı gereç kullanabileceği belirtilir (16).

Değerlendirme: A.Y. ROM egzersizlerini tedaviden sonra da yapacağını bildirmiştir.

\section{Benlik Kavramı Alanı}

Odak uyaran: Mide kanseri, cerrahi operasyon

Bağlamsal Uyaran: Kemoterapi tedavi süreci, ağrı hissetme korkusu

Rezidüel uyaran: Hastalık ile ilgili ileriye yönelik belirsizlik

\section{Hemşirelik Tanısı: Anksiyete}

Hemşirelik Girişimleri

- Anksiyete ile ilgili duygu ve düşüncelerin ifade edilmesine firsat verilir.

- Ağrıya neden olan aktivitelerin belirlenmesi ve cerrahi insizyon bölgesinde oluşabilecek ağrı hakkında bilgi verilir.

- Kemoterapi tedavi süreci açıklanır.

- Sakin, destekleyici bir şekilde bakım verilir.

- Bireyin var alan baş etme yöntemleri değerlendirilerek kullanması için cesaretlendirilir (16, 17).

Değerlendirme: A.Y. bundan sonraki süreç hakkında bilgi sahibi olduğu için kendini daha iyi hissettiğini ifade etti.

Odak uyaran: Mide kanseri

Bağlamsal uyaran: Kemoterapi tedavi süreci, yaş

Rezidüel uyaran: Hastalık ile ilgili ileriye yönelik belirsizlik

Hemşirelik Tanısı: Kemoterapi tedavi sürecine yönelik bilgi eksikliği

Hemşirelik Girişimleri

- Bireyin ve yakının hastalık ve kemoterapi tedavi süreci ile ilgili bilgi düzeyleri değerlendirilir.

- Birey ve yakınlarına cerrahi sonrası süreç ve kemoterapi tedavi süreci anlayabilecekleri bir dil ile anlatılır.

- Kemoterapi tedavi sürecinde kürü almaya geleceği zaman, kan vermeye geleceği zamanlar hakkında bilgilendirilir.

- Kemoterapi tedavisinde alacağı ilacın etkisi, yan etkisi, bu süreçteki beslenmesi, sağlık kuruluşuna başvurması gereken durumlar anlatılır.

- Birey veya yakınına eğitim konularını içeren broşür verilir.

- Duygu ve düşüncelerini aktarması için cesaretlenir (18).

Değerlendirme: Birey ve kızı kemoterapi tedavi süreci ve dikkat etmesi gerekenler hakkında bilgi sahibi olduklarını ilettiler.

\section{Rol Fonksiyon Alanı}

Odak uyaran: Mide kanseri

Bağlamsal Uyaran: Kızlarına bağımlı olma korkusu

Rezidüel uyaran: Aktivitelerde kısıtlılık 
Hemşirelik Tanısı: Bireysel Baş etmede Yetersizlik Hemşirelik Girişimleri

- Birey yakınları ile olan ilişkisini tanımlanması yönünde desteklenir.

- Bireyin sorunların çözümünde yakınları ile etkili iletişimi sürdürerek etkili baş etme yöntemlerinin geliştirilmesi konusunda cesaretlendirilir.

- Bireyin baş etme stratejileri belirlenir ve kullanması konusunda cesaretlendirilir.

- Bireyin yakınlarının kemoterapi tedavisi hakkındaki görüşleri belirlenir $(16,19)$.

Değerlendirme: Birey tedavisin takibini ve bazı bakım gereksinimlerini kızları karşılayacağı için kendini kötü hissettiğini belirtti.

\section{Karşılıklı Bağlılık Alanı}

Odak uyaran: Mide kanseri, kemoterapi tedavisi

Bağlamsal Uyaran: Kızının bu süreçte annesinin yanında olacağını belirtmesi

Rezidüel Uyaran: Bireyin kendini kızlarının yanında olmasından dolayı güvende hissetmesi

\section{Hemşirelik Tanısı: Aile İçi Süreçlerde Güçlenmeye Hazır Oluş}

Hemşirelik Girişimleri

- Ailenin durumunu değerlendirmesine yardım edilir.

- Aile içi mahremiyeti koruyucu bir ortamda iletişim sürdürülür.

- Bireyden beklentilerini gerçekçi bir şekilde değiştirmeleri için kızlarına yardım edilir.

- Ailenin güçlü yönleri onaylanır (Kızınız sizinle çok ilgili gibi).

- Tedavi süreci hakkında tam bilgi verilerek gerçekçi bakış açısına sahip olmaları için aile üyeleri cesaretlendirilir.

- Gerekirse profesyonel destek alması gerektiği söylenir $(18,20)$

Değerlendirme: A.Y kızlarının kendisine daha yakın davrandığını ifade etti.

\section{TARTIŞMA}

Klinik uygulamada model kullanımı çoğu zaman karmaşık ve kapsamlı bir süreç olmasına rağmen oldukça önemli yararları bulunmaktadır. Roy'un Uyum modelinde dört adaptasyon biçimi ve üç adaptasyon düzeyi hemşirelere hemşirelik sürecini tanılama, birey ve çevresi için neleri gözden geçirmesine ilişkin bir alt yapı oluşturmaktadır. Modele göre hemşireler uyaranları bulmak ve uyaranlara yönelik hemşirelik girişimlerini planlayarak bireyin verdiği uygun yanıtı artırmalıdırlar. Bu olumlu yanıt sadece bireyi değil çevresini de etkileyerek elde edilir. Bütüncül bir bakış açısına sahip olan bu model ile mide kanseri tanısı aldıktan sonra, cerrahi sonrası ilk kemoterapi kürünü almaya gelen hastanın hemşirelik bakım süreci anlatılmıştır. Olguda modele göre tanımlanan dört uyum alanında da uyumsuz yanıtlar geliştiği görülmüştür. Birey bu uyaranlara olumlu yanıt geliştirebilse hemşirelik girişimleri olumlu, geliştiremez ise olumsuz olarak nitelendirilmektedir.

Bireye fizyolojik alanda; fiziksel harekette bozulma, benlik kavramı alanında; anksiyete, kemoterapi tedavi sürecine yönelik bilgi eksikliği, rol fonksiyon alanında; bireysel baş etmede yetersizlik, karşılıklı bağlılık alanında; aile içi süreçlerde güçlenmeye hazır oluş tanıları koyularak uygun hemşirelik girişimleri uygulanmıştır. Uygulanan girişim sonucunda bireyin fizyolojik alanda fiziksel mobilitesine yönelik girişimleri anlayıp bu girişimlere devam edeceğini iletmesi, benlik kavramı alanında anksiyete düzeyinin ve tedavi sürecine yönelik bilgi eksikliğinin azaldığını bildirmesi, karşılıklı bağlılık alanında aile içi süreçlerde güçlenmeye hazır oluşları olumlu yanıt olarak değerlendirilmiştir. Ancak bireyin rol fonksiyon alanında bireysel baş etme sistemlerinin etkin olmadığı saptanmıştır. Her bir uyum alanının birbiri ile etkili olduğu düşünülünce rol fonksiyon alanının diğer alanları da etkileyeceği düşünülmüştür. $\mathrm{Bu}$ sebeple bireyin bireysel baş etmede yaşadığı güçlüğü azaltmak amacıyla veri toplama aşamasına tekrar dönülmesi ve uygun hemşirelik girişimlerinin uygulanması önerilmektedir.

Makalede, ilk kemoterapi kürünü almaya gelen mide kanserli hastanın RAM 'ne göre hemşirelik bakım planı hazırlanmış, bireyin fizyolojik, benlik kavramı, rol fonksiyon ve karşılıklı bağlılık alanlarında olumlu uyum yanıtları geliştirmesi hedeflenmiştir. Planlanan hemşirelik süreci ile hastanın kemoterapi tedavi sürecine optimum uyumu sağlanmıştır. Bu sebeple Roy Uyum Modeli'nin kemoterapi alan hastalarda kullanımının uygun olduğu ve bu çalışmanın rehber niteliği taşıyacağı sonucuna varılmıştır.

Çıkar Çatışması: Çalışmada herhangi bir çıkar çatışması yoktur.

Finansal Çıkar Çatışması: Çalışmada herhangi bir finansal çıkar çatışması yoktur.

Yazışma Adresi: Handan Eren, Karamanoğlu Mehmetbey Üniversitesi Sağlık Bilimleri Fakültesi Hemşirelik Esasları Anabilim Dalı, Yunus Emre Yerleşkesi 70200, Karaman, Türkiye e- mail: erennhandan@gmail.com

\section{KAYNAKLAR}

1. Ferlay J, Soerjomataram I, Dikshit R, et al. Cancer incidence and mortality worldwide: Sources, methods and major 
patterns in Globocan 2012. Int J Cancer 2015;136(5): E35986.

2. Yalçın B, Zengin N, Aydın F, et al. The clinical and pathological features of patients with gastric cancer in Turkey: A Turkish oncology group study. Turk J Cancer 2006;36:108-15.

3. Meijer S, De Bakker Oj, Hoitsma HF. Palliative resebtion in gastric cancer. J Surg Oncol 1983;23(2):77-80.

4. Kurihara M, Aiko T. The new Japanese classification of gastric carcinoma: Revised explanation of "response assessment of chemotherapy and radiotherapy for gastric carcinoma." Gastric Cancer 2001;4(1):9-13.

5. Thuss-Patience PC, Krezschmar A, Bıchev D, et al. Survival advantage for irinotecan versus best supportive care as second-line chemotherapy in gastric cancer: A randomised phase III study of the arbeitsgemeinschaft internistische onkologie (AIO). Eur J Cancer 2011;47(15): 2306-14.

6. Kamen C, Tejani MA, Chandwani K, et al. Anticipatory nausea and vomiting due to chemotherapy. European J Pharma 2014;5(722):172-9.

7. Chan HK, İsmail S. Side effects of chemotherapy among cancer patients in a Malaysian general hospital: Experiences, perceptions and informational needs from clinical pharmacists. Asian Pac J Prev 2015;15(13): 5305-9.

8. Galluzzi L, Buque A, Kepp O, et al. Immunological effects of conventional chemotherapy and targeted anticancer agents. Cancer Cell 2015;28(6):690-714.

9. Ünsar S, Fındık YÜ, Kurt S, et al. Kanserli hastalarda evde bakım ve semptom kontrolü. Fırat Sağlık Hizmetleri Dergisi 2007;2(5):89-106.

10. Fawcett J. Contemporary nursing knowledge analysis and evoulation of nursing models and theories. 2th ed. Philadelphia: Fa Davis company 2005:364-437.
11. Kaçaroğlu VA. Hemşirelik bakımında model kullanımına bir örnek: Modifiye radikal mastektomi olmuş bir bayanın, roy adaptasyon modeline göre incelenmesi. Maltepe Üniversitesi Bilim ve Sanat Dergisi 2010;2:106-18.

12. Uzun Ş. Hemşirelik teorileri ve modelleri. Karadağ $A$, Çalışkan N, Göçmen Baykara Z, ed. Sister callista roy: Adaptasyon modeli. Akademi basın ve yayıncılık, İstanbul 2017:370-437.

13. Roy C. The roy adaptation model. 3rd ed. New Jersey upper saddle river: Pearson Prentice Hall Health 2009:35-50.

14. Roy S. Extending the roy adaptation model to meet changing global needs. Nursing Science Quarterly 2011;24:345-51.

15. Ardashir A, Karimi Z, Hassani P. Roy's adaptation modelbased patient education for promoting the adaptation of hemodialysis patients. Iranian Red Crescent Med J 2013;15(7):566-72.

16. Birol L. Hemşirelik süreci hemşirelik bakımında sistematik yaklaşım: Açıklanan hemşirelik tanıları. 10.Baskı. Etki Yayınları, İzmir 2011:78-82.

17. Çıtlık Sarıtaş $S$, Büyükbayram Z. Kemoterapi alan hastaların ve bakım veren yakınlarının anksiyete düzeyleri ve etkileyen faktörler. TAF Preventive Medicine Bulletin 2016;15(2):14150.

18. Carpenito-Moyet LJ. Hemşirelik tanıları: El kitabı (F. Erdemir, Çev.) İstanbul: Nobel Tıp Kitabevleri 2010:136-544.

19. Pınar Ş, Tel H. Depresyon tanılı birey ve hemşirelik yaklaşımı. Psik Hemş Derg 2012;3(2):86-91.

20. Buzlu S, Daştan. Kanser hastalarının yaşamı/başetme In: Can G. Onkoloji hemşireliğinde kanıta dayalı bakım. İstanbul: İstanbul Konsensusu Nobel Tıp Kitapevi 2010: 281-299. 